\title{
CONDIÇÕES HIGIÊNICO-SANITÁRIAS NO COMÉRCIO AMbulante DE ALIMENTOS EM PELOTAS-RS 1
}

\author{
Kelly Lameiro RODRIGUES ${ }^{2,3}$, Juliana Pinto GOMES ${ }^{2}$, Rita de Cassia dos Santos da CONCEIÇÃO ${ }^{3}$, \\ Claudiomar Soares BROD, José Beiro CARVALHAL ${ }^{2}$, José Antonio Guimarães ALEIXO 2,3,*
}

\begin{abstract}
RESUMO
O comércio de alimentos prontos para o consumo por vendedores ambulantes pode constituir um alto risco para a saúde dos consumidores, visto que as pessoas envolvidas nesta atividade geralmente não tem preparo para a manipulação correta de alimentos. Neste trabalho foram investigadas as condições de preparo e a qualidade higiênico-sanitária de lanches comercializados por vendedores ambulantes em Pelotas. Foram colhidas de 60 estabelecimentos, uma amostra de água, uma da superficie de manuseio e um lanche (cachorroquente). Nos cachorros-quentes foram realizadas contagens de bactérias aeróbias mesófilas (BAM), Staphylococcus coagulase positiva (STA), coliformes totais (CT), coliformes a $45^{\circ} \mathrm{C}(\mathrm{CF})$, e investigada a presença de Salmonella sp. Na água e superficie foram realizadas contagens de BAM, CT e CF. Entre as 60 amostras de cachorros-quentes analisadas, 53\%, 48\%, 37\% e $25 \%$ estavam fora do padrão para CT, BAM, STA e CF, respectivamente. Em nenhuma amostra foi detectada a presença de Salmonella. As amostras de água apresentaram apenas $3(5 \%)$ amostras fora do padrão para BAM, e 27\% e 23\% fora do padrão para CT e CF, respectivamente. Em relação às superficies, $70 \%$ foram consideradas insatisfatórias para contagem de BAM e $68 \%$ e $67 \%$ para CT e CF. Os resultados sugerem que as condições higiênicas existentes em muitos estabelecimentos não são adequadas, o que se reflete em uma proporção relativamente alta de lanches com qualidade microbiológica insatisfatória para o consumo.
\end{abstract}

Palavras-chave: vendedores ambulantes; qualidade higiênico-sanitária; cachorro-quente.

\section{SUMMARY}

HYGIENIC-SANITARY CONDITIONS OF STREET FOODS FROM PELOTAS, RS. Street-vending of ready-to-eat (RTE) foods can be a risk to the consumers health, since people usually involved in this activity does not have proper knowledge in safe handling of foods. Despite this, only a few studies have been made on the microbiological quality of these foods and places where they are prepared. In this paper we report on the higienic-sanitary quality of hot-dogs sold by street-vendors from Pelotas, RS. Samples of hot-dogs, water and work surfaces, were collected from 60 street-vending places and taken to the laboratory for analysis. Counts of aerobic mesophilic bacteria (TPC), Staphylococcus coagulase positive (SCP), total coliforms (TC) and coliforms at $45^{\circ} \mathrm{C}$ (FC) were made on samples of hot-dogs. SPC, TC and FC counts were made on the water and surface samples. Among the 60 samples of hot-dogs $53 \%$, $48 \%, 37 \%$ and $25 \%$ were found unsatisfactory for TC, TPC, STA and FC, respectively. Only $3(5 \%)$ water samples were found unsatisfactory according to the TPC standard used, and $27 \%$ and $23 \%$ did not read the standards for TC and FC. Regarding the surfaces, $70 \%$ were found unsatisfactory for TPC, $68 \%$ for TC and $67 \%$ for FC. Salmonella sp was not detected in any of the samples tested. These results suggest that the hygiene practices of many food street-vending places are not adequate, resulting in a high proportion of read-to-eat RTE) foods with microbiological quality unsatisfactory for consumption.

Keywords: street-vending; microbiological quality; hot-dogs.

\section{1 - INTRODUÇÃO}

O preparo e comércio de alimentos por ambulantes nas ruas das grandes cidades é um fenômeno mundial e tem especial importância nos países em desenvolvimento, onde constitui uma atividade econômica alternativa para os desempregados [4]. Devido a problemas sócioeconômicos de vários países, este setor da economia tem crescido bastante nas últimas décadas. Este fato, junto com a urbanização e o crescimento da população, faz com que se espere um crescimento ainda maior deste tipo de comércio [26].

Estudos realizados na América Latina, estimam que 25 a $30 \%$ do gasto familiar nos grandes centros urbanos se destinam ao consumo de alimentos comercializados por vendedores de alimentos ambulantes [12]. Geralmen-

\footnotetext{
1. Recebido para publicação em 22/06/2002. Aceito para publicação em 02/04/2003 (000867).

2. Faculdade de Nutrição - Universidade Federal de Pelotas - Cx. 354 CEP96010-900 email: biotjaga@ufpel.tche.br

3. Programa de Pós-Graduação em Ciência e Tecnologia Agroindustrial FAEM - Universidade Federal de Pelotas - CEP 96010-900

4. Centro de Zoonoses - Faculdade de Veterinária - Universidade Federal de Pelotas

* A quem a correspondência deve ser enviada.
}

te os alimentos vendidos por ambulantes são produtos prontos para o consumo, preparados no próprio local de comercialização que está situado em regiões de grande afluência de público [7]. Os produtos comercializados diferem entre os diversos paîses e culturas e também apresentam grande importância do ponto de vista turístico, pois muitos são produtos típicos de uma região, sendo muito apreciados pelos turistas.

Em contraponto este tipo de comércio pode constituir um risco à saúde da população, pois os alimentos podem ser facilmente contaminados com microrganismos patogênicos, devido as condições inadequadas do local de preparo e a falta de conhecimentos de técnicas de manipulação higiênica por parte dos comerciantes. Além disso, muitos estabelecimentos de comércio ambulante não contam com sistema de abastecimento de água tratada, o que dificulta a higienização correta dos utensílios utilizados no preparo das refeições. Utensilios, superficies e equipamentos insuficientemente limpos representam um risco de contaminação, especialmente para alimentos cozidos que não serão consumidos imediatamente [24].

Nos países em desenvolvimento, onde é comum este tipo de comércio, produtos prontos para o consumo não 
são freqüentemente associados a surtos de toxinfecções alimentares, o que talvez se deva a inexistência de dados epidemiológicos adequados [1]. Contudo, vários trabalhos sobre a qualidade de alimentos comercializados em vias públicas, realizados em diversos países da África e da América Latina sugerem que estes alimentos podem ser fontes de toxinfecção alimentar $[10,11,16,23]$.

No Brasil, estudos realizados com alimentos comercializados por ambulantes em diversas regiões demonstraram que este tipo de produto pode representar um risco para saúde pública $[9,22,25]$. Na região Sul, mais especificamente no Rio Grande do Sul, são poucas as informações sobre a qualidade de alimentos comercializados na rua. Assim, este trabalho teve por objetivo investigar a qualidade higiênico-sanitária de lanches e as condições de preparo e manipulação de alimentos vendidos por ambulantes na cidade de Pelotas.

\section{2 - MATERIAL E MÉTODOS}

\section{1 - Coleta e preparo das amostras}

Com o auxilio da Vigilância Sanitária Municipal de Pelotas foram colhidas amostras de lanches e do ambiente de preparo em 60 estabelecimentos de comércio ambulante de alimentos escolhidos aleatoriamente entre os que possuiam registro na Vigilância Sanitária. Deste total, 40 estabelecimentos eram do tipo "Trailer" e 20 do tipo "Towner". Foi feita a colheita de 15 amostras em cada estação do ano 2001. As amostras foram transportadas ao Laboratório de Análise de Alimentos da Faculdade de Nutrição, sob refrigeração, para realização das análises.

Em cada estabelecimento foram colhidas amostras de água, da superficie de manuseio e um cachorro-quente, que é o lanche mais popular e, por isso, sempre disponivel em todos os locais de comércio. Durante a colheita das amostras foi aplicado um questionário (Figura 1) aos funcionários visando à obtenção de informações sobre as práticas de preparação e conservação dos alimentos.

Questionário

Nome do estabelecimento:

Endereço:

Amostras:

Data: Hora da coleta:

1. Uso de jóias ou adornos? ( )sim ( )não

2. Unhas aparadas e limpas? ( ) sim ( )não

. Cabelos protegidos por luvas, boné ou rede? ( )sim ( )não

4. Usa-se luvas para o preparo dos lanches? ( ) sim ( )não

5. A pessoa que manipula os alimentos é a mesma que manipula o dinheiro? ( )sim ( )não

6. Existe algum cronograma de limpeza geral? ( )sim ( )não

7. Qual o destino do lixo?

. Apresenta sistema de abastecimento de água? ( )sim ( )não

9. Como são armazenados os alimentos perecíveis?

10. Como é feita a higienização dos vegetais?

11. Com qual produto a superfície de manipulação é limpa entre os lanches?

( ) pano de prato ( ) perflex ( )esponja ( ) outro

FIGURA 1. Questionário aplicado para obtenção de informações sobre as práticas de preparação e conservação dos alimentos.

As amostras de cachorro-quente foram acondicionadas em saco plástico estéril. As amostras de água foram colhidas em saco plástico estéril com capacidade para $100 \mathrm{~mL}$ contendo tiossulfato de sódio. As amostras das superficies foram coletadas em $50 \mathrm{~cm}^{2}$ do local de manuseio dos lanches através de zaragatoa e colocadas em tubos contendo $10 \mathrm{~mL}$ de água peptonada $0,1 \%$.

Foram pesados $25 \mathrm{~g}$ do cachorro-quente de forma a conter todos os ingredientes, adicionados a $225 \mathrm{~mL}$ de água peptonada 0,1\%, e homogeneizados em Bag Mixer (Interscience Inc., France). A partir desta diluição e das amostras de água e de superficie, foram preparadas diluições decimais suficientes para realizar as contagens.

\section{2 - Análises microbiológicas}

A metodologia utilizada nas análises microbiológicas foi a recomendada no Bacteriological Analytical Manual [15]. No cachorro-quente foram realizadas contagens de bactérias aeróbias mesófilas, coliformes totais, coliformes a $45^{\circ} \mathrm{C}$, Staphylococcus coagulase positiva e investigada a presença de Salmonella sp. Na superficie de manuseio foram realizadas contagens de bactérias aeróbias mesófilas, coliformes totais e coliformes a $45^{\circ} \mathrm{C}$. Na água foi realizado teste de presença/ausência de coliformes totais e coliformes a $45^{\circ} \mathrm{C}$ em $100 \mathrm{~mL}$ e contagem de bactérias aeróbias mesófilas.

\subsection{1 - Contagem de bactérias aeróbias mesófilas}

Para a contagem de bactérias aeróbias mesófilas foi semeado $1 \mathrm{~mL}$ de cada diluição em placas de Petri em duplicata, acrescentando-se a seguir 18 a $20 \mathrm{~mL}$ de ágar padrão para contagem (Difco). Após incubação a $37^{\circ} \mathrm{C}$ por 48 horas foi feita a contagem das colônias.

\subsection{2 - Determinação de coliformes totais e coliformes a $45^{\circ} \mathrm{C}$}

A metodologia do Número Mais Provável foi utilizada para realizar a estimativa do número de coliformes totais e coliformes a $45^{\circ} \mathrm{C}$ nas amostras de cachorroquente e superficie. A partir das diluições foram inoculadas séries de três tubos contendo $10 \mathrm{~mL}$ de caldo lauril sulfato triptose (Difco), incubando-se a $37^{\circ} \mathrm{C}$ por 48 horas. Após o período de incubação, dos tubos positivos (com formação de gás) as culturas foram repicadas com alça de platina para os tubos de caldos lactose bile verde brilhante (LBVB) (Difco) e EC (Difco) e incubados a $37^{\circ} \mathrm{C}$ e $45^{\circ} \mathrm{C}$, respectivamente, por 48 horas. Os tubos positivos nos caldos LBVB e EC, confirmavam a presença de coliformes totais e coliformes a $45^{\circ} \mathrm{C}$. A estimativa do número de coliformes foi realizada com base em tabela do NMP. Para análise da água, 100mL da amostra e $100 \mathrm{~mL}$ de caldo lactosado duas vezes concentrado foram homogeneizados e incubados a $37^{\circ} \mathrm{C}$ por 48 horas. Destas culturas foram realizados repiques com alça de inoculação para um tubo contendo caldo LBVB e outro contendo caldo EC incubando-se, respectivamente, a $37^{\circ} \mathrm{C} \mathrm{e} 45^{\circ} \mathrm{C}$ por 48 horas. Os tubos de caldos LBVB e EC positivos confirmavam a presença de coliformes a $37^{\circ} \mathrm{C}$ e $45^{\circ} \mathrm{C}$. 


\subsection{3 - Contagem de Staphyloccoccus coagulase positiva}

Para a contagem de Staphyloccoccus coagulase positiva foi semeado $1 \mathrm{~mL}$ de cada diluição em três placas de Petri $(0,33 \mathrm{~mL} /$ placa) contendo ágar Baird-Parker (Difco) adicionado de telurito de potássio e gema de ovo. Com o auxílio da alça de Drigalsky espalhou-se o inóculo por toda superficie do meio até total absorção. Após incubar as placas por 48 horas a $37^{\circ} \mathrm{C}$ realizava-se a contagem presuntiva de Staphyloccoccus coagulase positiva. Pelo menos cinco colônias suspeitas foram cultivadas por 24 horas a $37^{\circ} \mathrm{C}$ em caldo infusão de cérebro e coração (BHI) (Difco) para se realizar o teste da coagulase. Para este teste misturou-se em tubos estéreis $0,25 \mathrm{~mL}$ do cultivo em BHI com 0,25mL de plasma de coelho coletado com citrato de sódio a $5 \%$ e incubou-se a $35^{\circ} \mathrm{C}$ por 6 horas. Após este período verificava-se o número de cultivos nos quais houve a formação de coágulos e calculava-se o número total de colônias coagulase positivas.

\subsection{4 - Pesquisa de Salmonella sp}

Inicialmente foi feito um pré-enriquecimento adicionando-se $25 \mathrm{~g}$ de amostra de cachorro-quente a $225 \mathrm{~mL}$ de caldo lactosado (Difco) e, a seguir, incubando-se a $37^{\circ} \mathrm{C}$ por 24 horas. Após a incubação, transferiu-se $1 \mathrm{~mL}$ para caldo tetrationato (Difco) contendo iodo e verde brilhante e $0,1 \mathrm{~mL}$ para caldo Rapapport Vassiliadis (Difco), seguido de incubação a $42^{\circ} \mathrm{C}$ por 24 horas. A partir destes meios de enriquecimento seletivo semeou-se agar xilose-lisina-desoxicolato e agar Hektoen (Difco), seguido de incubação a $37^{\circ} \mathrm{C}$ por 24 horas. A seguir, 3 a 5 colônias suspeitas eram transferidas para agar TSI, LIA e caldo uréia. Os isolamentos com reações características eram então confirmados com soro anti-Salmonella polivalente somático (Probac).

TABELA 1. Padrões e recomendações utilizados para classificação dos resultados das análises bacteriológicas realizadas nos lanches, água e superficie de manuseio.

\begin{tabular}{ll}
\hline \multicolumn{1}{c}{ Amostra/Análise } & Limite aceitável \\
\hline Cachorro-quente & \\
Bactérias aeróbias mesófilas & $10^{5} \mathrm{UFC} / \mathrm{g}^{5}$ \\
Coliformes totais & $10^{2} \mathrm{UFC} / \mathrm{g}$ \\
Coliformes a $45^{\circ} \mathrm{C}$ & $10^{2} \mathrm{UFC} / \mathrm{g}^{1}$ \\
Staphylococcus coagulase positiva & $10^{3} \mathrm{UFC} / \mathrm{g}^{1}$ \\
Salmonella sp & Ausência em $25 \mathrm{~g}^{1}$ \\
& \\
Água & \\
Bactérias aeróbias mesófilas & $5 \times 10^{2} \mathrm{UFC} / \mathrm{mL}^{2}$ \\
Coliformes totais & Ausência em $100 \mathrm{~mL}^{3}$ \\
Coliformes a $45^{\circ} \mathrm{C}$ & Ausência em $100 \mathrm{~mL}^{3}$ \\
Superfícies de manuseio & \\
Bactérias aeróbias mesófilas & $50 \mathrm{UFC} / \mathrm{cm}^{2} 4$ \\
Coliformes totais & Ausência em $50 \mathrm{~cm}^{2} 4$ \\
Coliformes a $45^{\circ} \mathrm{C}$ & Ausência em $50 \mathrm{~cm}^{2}{ }^{4}$ \\
\hline
\end{tabular}

1 Resolução - RDC nำ 12, de 2 de janeiro de 2001 2 Portaria no 36/GM, de 19 de janeiro de 1990 3 Portaria no 1469 , de 29 de dezembro de 2000 4 Silva [26]

5 Gilbert, et al. [21]2.3 - Critérios de avaliação

\section{3 - Critérios de avaliação}

Os resultados das análises bacteriológicas realizadas nos lanches, água e superficie de manuseio, foram classificados como satisfatório ou insatisfatório com base em padrões da legislação brasileira e, na falta destes, em recomendações disponiveis na literatura [19], conforme é mostrado na Tabela 1.

\section{4 - Análise estatística}

Os dados foram computados no Programa Epi Info Versão 6.04 [13] para avaliar a freqüência das bactérias indicadoras de qualidade higiênico-sanitária nos cachorros-quentes, água e superfície de preparo. Foi usado o teste $\chi^{2}$ (Qui-quadrado) de Mantel-Haenzsel para tendência linear e "odds ratio"(OR) no intervalo de confiança de 95\% para avaliar a existência de relação entre fatores de risco identificados no questionário e os resultados das análises bacteriológicas.

\section{3 - RESULTADOS E DISCUSSÃO}

Os resultados das análises bacteriológicas realizadas nos cachorros-quentes são mostrados na Tabela 2.

TABELA 2. Resultados de análises bacteriológicas realizadas em cachorros-quentes vendidos no comércio ambulante de Pelotas-RS, 2001.

\begin{tabular}{lcc}
\hline \multicolumn{1}{c}{ Análise } & $\begin{array}{c}\text { Insatisfatório } \\
(\%)\end{array}$ & Satisfatório \\
& $(\%)$ \\
\hline Bactérias aeróbias mesófilas & 48 & 52 \\
Coliformes totais & 53 & 47 \\
Coliformes a $45^{\circ} \mathrm{C}$ & 25 & 75 \\
Staphylococcus coagulase positiva & 37 & 63 \\
Salmonella sp & 0 & 100 \\
\hline $\mathrm{n}=60$ & &
\end{tabular}

Os coliformes constituem um grupo de enterobactérias presentes nas fezes e no ambiente, como o solo e as superficies de vegetais, animais e utensílios. A sua pesquisa nos alimentos é utilizada como indicador da qualidade higiênico-sanitária. Os coliformes são geralmente subdivididos em dois grupos: (i) totais (coliformes a $37^{\circ} \mathrm{C}$ ), que são oriundos do ambiente e usados como indicadores da qualidade higiênica dos alimentos e (ii) fecais (coliformes a $45^{\circ} \mathrm{C}$ ), que são provenientes de uma contaminação fecal recente e usados como indicadores da qualidade sanitária dos alimentos [17]. Como a atual legislação brasileira não estabelece padrão de aceitabilidade para coliformes totais em nenhum tipo de alimento, a classificação dos resultados em satisfatório/ insatisfatório para este indicador foi realizada com base no padrão utilizado para coliformes fecais, fixa em até $10^{2} \mathrm{UFC} / \mathrm{g}$ o limite máximo permitido neste tipo de produto alimentício.

Em 53\% dos estabelecimentos estudados foram obtidos NMPs de coliformes totais nos cachorros-quentes considerados insatisfatórios. Este resultado contrasta com os obtidos em dois estudos similares realizados 
em outras localidades, onde foram encontrados $11 \%$ e $0 \%$ de amostras insatisfatórias para este grupo de bactérias $[3,18]$. Com relação aos NMPs de coliformes fecais, $25 \%$ dos lanches apresentaram valores acima do limite aceito na legislação brasileira. Comparando este resultado com os obtidos nos dois estudos anteriormente mencionados, nos quais foram encontrados $4 \%$ e $0 \%$ de amostras insatisfatórias para estes indicadores, nosso estudo revela que de quatro cachorros-quentes vendidos, um é impróprio para o consumo.

A presença de bactérias aeróbias mesófilas em números elevados é comum em alimentos crus e naqueles produzidos artesanalmente [21], principalmente quando a produção e a comercialização ocorre em vias públicas, com exposição às condições ambientais. Pelo critério utilizado, a contagem de bactérias aeróbias mesófilas nos lanches estava fora do aceitável em $52 \%$ dos estabelecimentos pesquisados, variando entre $10^{5}$ e $10^{6} \mathrm{UFC} / \mathrm{g}$. Em trabalho realizado em outra cidade brasileira foram encontradas $100 \%$ das amostras com contagens superiores a $10^{4} \mathrm{UFC} / \mathrm{g}$, e $73 \%$ acima de $10^{6} \mathrm{UFC} / \mathrm{g}$ [9]. Também foram encontradas contagens elevadas de bactérias aeróbias mesófilas em estudos realizados com vendedores ambulantes em outros países com caracteristicas sócio-econômicas similares ao Brasil $[8,23]$.

A pesquisa de Staphylococcus coagulase positiva é importante neste tipo de produto, porque além de ser um grupo de bactérias potencialmente patogênicas sua presença em contagens elevadas indica falta de higiene na manipulação dos lanches [17]. De acordo com os resultados obtidos, $37 \%$ das amostras estavam fora do limite aceitável. Em outros dois estudos realizados em cidades brasileiras apenas uma amostra foi considerada insatisfatória [9,18].

Em nenhuma amostra de cachorro-quente analisada neste estudo foi constatada a presença de Salmonella. Entre as amostras de cachorros-quentes analisadas em outros três estudos apenas uma foi positiva para Salmonella $[2,3,25]$, o que sugere que a prevalência desta bactéria é baixa neste tipo de produto. Embora não se tenha detectado contaminação por Salmonella, os números de bactérias indicadoras de qualidade higiênicosanitária observados foram altos em uma proporção significativa de lanches, indicando que maiores cuidados com a higiene devem ser tomados na sua elaboração e comercialização.

Os resultados das análises bacteriológicas dos cachorros-quentes vendidos nos estabelecimentos do tipo "Trailer" e nos do tipo "Towner" não apresentaram diferença significativa $[p>0,05]$, embora tenha sido demonstrado em outro estudo que os estabelecimentos do tipo "Towner" apresentam melhores condições higiênico-sanitárias [24].

Os resultados das análises bacteriológicas realizadas na água utilizada pelos vendedores ambulantes são mostrados na Tabela 3.

Segundo o critério de qualidade utilizado para a água [5], $27 \%$ e $23 \%$ das amostras analisadas estavam fora dos padrões para coliformes totais e coliformes a $45^{\circ} \mathrm{C}$, respectivamente. Os NMPs de coliformes totais e coliformes a $45^{\circ} \mathrm{C}$ fora do padrão foram encontrados em maior percentual nas amostras coletadas de estabelecimentos do tipo "Trailer". Para contagem de bactérias aeróbias mesófilas o limite é de $500 \mathrm{UFC} / \mathrm{mL}$ [6] e apenas três amostras classificaram-se acima deste valor, sendo estas obtidas nos estabelecimentos do tipo "Towner", que não estão diretamente ligados ao sistema de abastecimento de água da rede pública. O questionário revelou que dos 60 estabelecimentos estudados, 17 $(28 \%)$ não estavam ligados ao sistema público de abastecimento de água.

TABELA 3. Resultados das análises bacteriológicas realizadas nas amostras de água obtidas em estabelecimentos de comércio ambulante de alimentos em Pelotas-RS, 2001.

\begin{tabular}{lcc}
\hline \multicolumn{1}{c}{ Análise } & $\begin{array}{c}\text { Insatisfatório } \\
(\%)\end{array}$ & Satisfatório \\
& $(\%)$ \\
\hline Bactérias aeróbias mesófilas & 5 & 95 \\
Coliformes totais & 27 & 73 \\
Coliformes a $45^{\circ} \mathrm{C}$ & 23 & 77 \\
\hline
\end{tabular}

$\mathrm{n}=60$

Os resultados das análises bacteriológicas realizadas nas superficies de manuseio dos lanches são mostrados na Tabela 4. Com base nestes dados, 68\% das superficies analisadas foram consideradas insatisfatórias em relação ao NMP de coliformes totais e $67 \%$ em relação ao NMP de coliformes a $45^{\circ} \mathrm{C}$. Nas contagens de bactérias aeróbias mesófilas $70 \%$ das superficies de manuseio foram classificadas como insatisfatórias. Estes resultados demonstram falta de higiene adequada com relação ao ambiente de preparo dos lanches, o que pode refletir-se em um aumento na sua contaminação por bactérias patogênicas.

TABELA 4. Resultados das análises bacteriológicas realizadas em amostras obtidas na superfície de manuseio utilizadas por vendedores ambulantes em Pelotas-RS, 2001.

\begin{tabular}{lcc}
\hline \multicolumn{1}{c}{ Análise } & $\begin{array}{c}\text { Insatisfatório } \\
(\%)\end{array}$ & Satisfatório \\
& $(\%)$ \\
\hline Bactérias aeróbias mesófilas & 70 & 30 \\
Coliformes totais & 68 & 32 \\
Coliformes a $45^{\circ} \mathrm{C}$ & 67 & 33 \\
\hline
\end{tabular}
$\mathrm{n}=60$

Com base no questionário aplicado aos comerciantes durante a colheita das amostras, obteve-se informações sobre os procedimentos realizados pelos manipuladores durante o preparo dos lanches (Tabela 5).

Os resultados obtidos em relação ao questionário foram analisados em conjunto com os resultados das análises bacteriológicas através do programa Epi Info 6.0 [13]. Dos fatores de risco citados acima, a manipulação de alimentos e dinheiro pela mesma pessoa foi indicada como um fator de risco relacionado às altas contagens 
de bactérias aeróbias mesófilas. Isto pode ser explicado pelo fato das cédulas de dinheiro conterem um grande número de bactérias [20] e as pessoas que lidavam com dinheiro e alimento o faziam sem lavar as mãos, o que pode ocasionar altas contagens de bactérias nos lanches.

TABELA 5. Freqüência dos procedimentos realizados pelos manipuladores de alimentos no comércio ambulante em Pelotas-RS, 2001.

\begin{tabular}{lc}
\hline \multicolumn{1}{c}{ Procedimentos realizados por manipuladores } & Frequência (\%) \\
\hline Manipulação de alimentos e dinheiro & 58 \\
Unhas aparadas e limpas & 75 \\
Cabelos protegidos por touca ou boné & 57 \\
Uso de jóias e adornos & 55 \\
Uso de luva no preparo dos lanches & 32 \\
\hline
\end{tabular}

Quanto ao uso de luvas no preparo dos lanches, existem controvérsias sobre a sua eficácia com relação à higiene dos alimentos. A luva funciona como uma barreira física, mas está sujeita a rompimentos e, principalmente, pode facilitar o crescimento de microrganismos na pele, pois tapam as mãos, aumentando os niveis de umidade e nutrientes necessários para o seu desenvolvimento. A lavagem adequada das mãos seria mais eficiente para remoção ou diminuição dos microrganismos [14]. Neste trabalho encontrou-se baixo percentual de uso de luvas no preparo dos lanches e a análise estatística não mostrou relação significativa entre o não uso de luvas e as altas contagens de bactérias indicadoras encontradas nos lanches.

Durante o preparo dos alimentos deve ser removido qualquer adorno que não possa ser adequadamente desinfetado ou que possa cair no alimento e o manipulador deve ter o cuidado de manter suas unhas aparadas, limpas e sem esmalte. Neste trabalho verificou-se que 55\% dos vendedores usavam adornos e $75 \%$ apresentavam unhas limpas e aparadas, resultados que contrastam com os encontrados na cidade de São Paulo-SP [22] onde os percentuais encontrados foram de $83 \%$ e $30 \%$, respectivamente. Comparando os dois trabalhos observase que em Pelotas os manipuladores possuem maior cuidado com sua apresentação no local de trabalho.

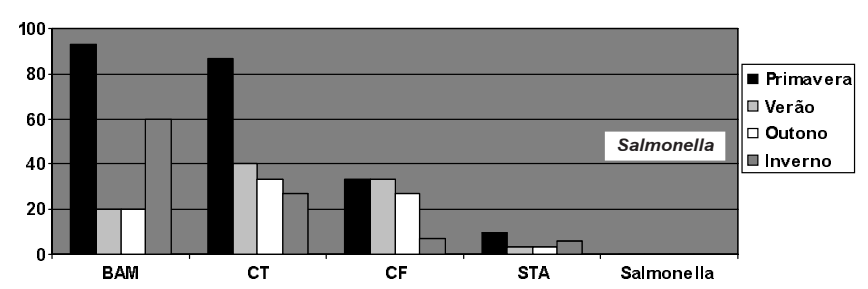

BAM - Bactérias aeróbias mesófilas CT - Coliformes totais

CF - Coliformes a $45^{\circ} \mathrm{C}$ - Staphylococcus coagulase positiva

FIGURA 2. Distribuição da porcentagem de amostras de lanche insatisfatórias de acordo com as estações do ano, no comércio ambulante de Pelotas-RS, 2001.
Na Figura 2 são apresentados resultados das análises bacteriológicas realizadas nos lanches nas diferentes estações do ano. São mostrados os resultados considerados insatisfatórios para os diferentes indicadores de acordo com os critérios já mencionados. Embora fosse esperada uma maior prevalência de lanches em condições insatisfatórias no verão, devido a temperaturas mais elevadas, observou-se que foi na primavera que ocorreu o maior percentual de lanches com baixa qualidade higiênica. Esta observação talvez possa ser explicada pelo fato de a temperatura média nesta estação em 2001 ter sido $2^{\circ} \mathrm{C}$ mais alta do que a média histórica, de acordo com a Estação Agroclimatológica da UFPel/EMBRAPA (Pelotas, RS) e, também, pelo fato de que no verão os comerciantes geralmente tomam maiores cuidados com a higiene devido à intensificação da fiscalização sanitária e ao aparecimento freqüente de noticias sobre toxinfecções alimentares.

\section{4 - CONCLUSÕES}

Uma proporção significativa de cachorros-quentes comercializados por ambulantes em Pelotas apresentaram qualidade higiênica insatisfatória. Dos estabelecimentos analisados, as superficies de manuseio de alimentos apresentaram higiene inadequada em cerca de $70 \%$, e a água apresentou contaminação por coliformes fecais em 25\%. Com base nestas observações é recomendável a realização de programas de treinamento de vendedores ambulantes, de forma a capacitá-los quanto a técnicas de higienização do local de trabalho, de preparo higiênico dos lanches e de higiene pessoal.

\section{5 - REFERÊNCIAS BIBLIOGRÁFICAS}

[1] ABDUSSALAM, M.; KAFERSTEIN, F.K. Inocuidad de los alimentos en la atención primaria de salud. Foro Mundial de la salud, v. 15, p. 430-435, 1994.

[2] ALMEIDA, I.B.C.C.; OLIVEIRA, J.V. Avaliação higiênico-sanitária de salsichas e molhos comercializados em carrinhos de cachorro-quente na área central de Campo Grande-MS. XXI Congresso Brasileiro de Microbiologia, Foz do Iguaçú, PR, 21 a 25 de outubro de 2001.

[3] ALVES, L.M.C.; MACEDO, S.M.; DA SILVA, A.F.F. Detecção de Salmonella sp em cachorros-quentes comercializados em vias públicas na cidade de São Luiz-MA. XXI Congresso Brasileiro de Microbiologia, Foz do Iguaçú, PR, 21 a 25 de outubro de 2001.

[4] ARAMBULO, P. ; ALMEIDA, C.R.; CUELLAR, J.; BELLOTO, A.J. Street food vending in Latin America. Bull. Pan. Am. Health Organ, v. 28, n. 4, p. 344-454, 1994.

[5] BRASIL. Ministério da Saúde. Portaria n. 1469, de 29 de dezembro de 2000. Aprova a Norma de Qualidade de Água para Consumo humano. Diário Oficial da União, Brasília, 21 de janeiro de 2001.

[6] BRASIL. Ministério da Saúde. Portaria n. 36/GM, de 19 de janeiro de 1990. Aprova normas e o padrão de potabilidade da água destinada ao consumo humano a serem observados em todo território nacional. Diário Oficial da União, Brasília, 25 de janeiro de 1990.

[7] BRYAN, F.L.; MICHANIE, S.C.; ALVAREZ, P. ; PANIAGUA, A. Critical control points of street-vended foods in the 
Dominican Republic. Journal of Food Protection, v. 51, p. $373-383,1988$

[8] BRYAN, F.L.; TEUFEL, P. ; RIAZ, P. ; ROCH, S.; QUADAR, F; MALIK, Z. Hazards and critical control points of vending operations at a railway station and bus station in Pakistan. Journal of Food Protection, v. 55, p. 534-541, 1992.

[9] CATANOZI, M.P. L.; MORELHÃO, C.C.; IURCI, K.M. Avaliação microbiológica de lanches vendidos em carrinhos de ambulantes na cidade de Araraquara, SP. Higiene Alimentar, v. 13, n. 66, p. 116-121, 1999.

[10] CUELLAR, J. Situación de la venta de alimentos en las calles en America Latina y el Caribe. Documento presentado en el taller latinoamericano FAO/OPS sobre control de los alimentos que se venden en las calles. Montevideo, UY, 9 a 13 de maio de 1994.

[11] CUELLAR, J. Alimentos de venta callejera y la transmisión del cólera en America del Sur. Documento presentado a la Consulta Conjunta de Expertos FAO/OPS/OMS sobre inocuidad y comercialización de alimentos frente a la epidemia de cólera. Buenos Aires, AR, 6 a 8 de abril de 1992.

[12] COSTARRICA, M.L.; MÓRON, C. Estrategias para el mejoramento de la calidad de los alimentos callejeros en America Latina y el Caribe. Food Nutr. Agric., v. 17-18, p. 47-57, 1996.

[13] DEAN, A. G., et al. Epi Info. Version 6.0. A word processing, database and statistics program for public health on IBM compatible microcomputers. Center for Diseases Control and Prevention. Atlanta, Georgia, 1994.

[14] FENDLER, E. J., et al. Handwashing and gloving for food protection. PartII. Effectiveness. Dairy, Food and Environmental Sanitation, v. 18, n. 12, p. 824-829, 1998.

[15] FOOD AND DRUG ADMINISTRATION. Bacteriological Analytical Manual. 8a ed., 1998.

[16] FREESE, E.; ROMERO-ABAL, M.E.; SOLOMONS, N. W. The street food culture of Guatemala City: a case study from downtown, urban park. Arch. Latinoam. Nutr., v. 48, n. 2, p. 95-103, 1998.
[17] FRANCO, B.D.G.M.; LANDGRAF, M. Microbiologia de alimentos. São Paulo: Atheneu, 1996.

[18] GARCIA-CRUZ, C.H.; HOFFMAN, F.L.; BUENO, S.M. Monitoramento microbiológico de lanches vendidos por ambulantes na parte central da cidade de São José do Rio Preto-SP. Higiene Alimentar, v. 14 , n. 75 , p. 48 51,2000

[19] GILBERT, R.J., et al. Guidelines for the microbiological quality of some ready-to-eat foods sampled at the point of sale. Commun Dis. Public Health, v. 3, p. 163$167,2000$.

[20] HAVAS, F. About the bacteriological state of notes and coins. Magyar Allatorvosok Lapja, v. 8, n. 122, p. 501-503,2000.

[21] LEITE, C.Q.F. et al. Pesquisa de enteropatógenos em alimentos cárneos crus. Rev. Ciência e Tecnol. Alim., v. 8, p. 155-166, 1988.

[22] LUCCA, A. Cachorro-quente comercializado em locais públicos: pontos críticos e características do mercado. São Paulo, 2000. 142p. Exame de Qualificação (Mestre em Saúde Pública) - Faculdade de Saúde Pública, Universidade de São Paulo (USP).

[23] MOSUPYE, F.M.; HOLY, A.V. Microbiological quality and safety of ready-to-eat street-vended foods in Johannesburg, South Africa. Journal of Food Protection, v. 62, n11, p. 1278-1284, 1999.

[24] SILVA JR., E. A. Manual de controle higiênico-sanitário em alimentos. São Paulo, 1995.

[25] SILVA, F.B., et al. Microbiological quality of street-vended foods marketed in Niteroi city-RJ. XXI Congresso Brasileiro de Microbiologia, Foz do Iguaçú, PR, 21 a 25 de outubro de 2001.

[26] WIRNANO, F.G.; ALLAIN, A. Street food in developing contries lessons from Asia. Food Nutr. Agric., v. 1, n. 1, p. 11-18, 1991.

\section{6 - AGRADECIMENTOS}

Ao CNPq pela concessão de auxílio financeiro à pesquisa, e à laboratorista Maria Joana Rodrigues pelo auxílio na execução das análises. 